\title{
Discussion on the Teaching Mode of 3D Print Design Course Peifeng $\mathrm{Li}^{1, \mathrm{a}}$ \\ ${ }^{1}$ Jiangsu Province Xuzhou Technician College, Xuzhou, Jiangsu, China, 221000 \\ ${ }^{a}$ email,
}

Keywords: Technical Engineering; Industrial Design; 3D Printing; Teaching Model

\begin{abstract}
D printing design course is a very theoretical and practical courses, in order to better carry out 3D design of classroom teaching, so that students learn industrial design courses efficiently, technical institutions of this course take "product guide, step by step progressive "teaching methods gradually implemented, through practice proved that the teaching model for our teaching improvement has a great role in promoting.
\end{abstract}

\section{Introduction}

The teaching mode is a kind of teaching activity which is carried out in a certain environment. It is mainly carried out under certain educational thoughts, teaching theories and learning theories. The teaching mode is based on certain teaching rules and teaching ideas. At the same time, the teaching process should follow a relatively stable method of strategic system. Teaching model is not only the teaching theory of the specific, but also a system of teaching experience, teaching model has a relatively stable structure of the structure of teaching activities, so the teaching model easy to understand, grasp and use, so the promotion and popularization of advanced teaching theory is very Important value. The following focus on industrial design and 3D print design courses teaching mode.

\section{The Overview of Industrial Design and 3D Printing Professional}

Industrial design and 3D printing professional to serve the local economic development-oriented, professional characteristics as the basis, the mechanism for the premise of innovation, personalized personnel training as a means to improve the quality of personnel training as the goal, deepen the teaching reform, strengthen the teaching staff, training center construction, teaching materials, students' comprehensive quality training, built the province's first-class characteristics of professional.

Taking Serve the Local Economic and Social Development as Orientation. At the same time, according to the personnel training and local needs, we making our hospital computer-aided design professional to maximize the role and the local formation of mutual benefit and common development of the situation for the local manufacturing industry transport high-skilled personnel [1].

Seize the Opportunity to Quickly Develop Professional Features. Do a good job of the current opportunities for the development of the manufacturing industry, the use of our hospital CAD, UG, 3DMAX technology applications, numerical control technology, mold design and manufacturing advantages, strengthen the professional characteristics, really people I have, I'm strong. Keep up with the manufacturing information engineering project shuttle, so that features more beautiful.

Take Mechanism Innovation for the Premise, Personalized Personnel Training as a Means to Improve the Quality of Personnel Training. Update the educational concept, establish a training mechanism with the application of the market, the dynamic feedback mechanism of teaching quality, the second classroom characteristics training mechanism, increase the intensity of professional reform and construction, pay attention to the construction of professional content, according to the new situation the students 'knowledge structure, the ability structure and gradually optimize the student computer-aided design expertise application platform, establish a quality 
education, technical education, skills education tower structure, so that students' personality is fully displayed in the market to find their own position to achieve their own value.

\section{Industrial Design and 3D Printing Course Teaching Model Construction Environment}

The Overview of the Course. Industrial design is a broad industrial design and narrow industrial design, in the teaching of industrial design is mainly product design, that is, the tools and equipment in the community to respond to the demand. It includes the design of materials, products and equipment for the maintenance and development of production and life. 3D printing, a technique of rapid prototyping technology, is a digital model based on the use of plastic or powdered metal and other adhesive materials, through the layer by layer to print the way to build objects. At present, this technology is popular, in the past, often in the mold manufacturing, industrial design and other fields are used in manufacturing models is now being used for the direct manufacture of some products.

The Career Goals of Industrial Design and 3D Printing Professional. After in-depth research and demonstration, our hospital decided to product design, mold manufacturing and industrial design and 3D printing professional foothold. Because the mold as a modern industrial production of one of the important equipment in the automotive, aircraft, tractors, electrical, instrumentation, electronics and other industrial sectors are widely used, and its forming parts complex shape, high precision, difficult processing, mold industry itself is high-tech industry is an important component, and even can be said that the development of mold manufacturing industry, leading the development of modern manufacturing technology. Industrial design and 3D printing professional students have a specific professional ability, making the students 'professional goals to increase the mold design, mold assembly and commissioning two positions, to expand the students' jobs; to mold design, manufacturing as a foothold, making The training of students 'CAD / CAM key ability is more convenient for students to master CAD / CAM technology, and is more conducive to the cultivation of students' innovation and practical ability. [2-3] At the same time through in-depth study, planning the industrial design and 3D printing professional comprehensive ability, which is conducive to the improvement of students' comprehensive ability.

\section{The Teachers Teaching Support Platform}

Teachers can actively create industrial design and 3D courses personalized courses website teachers can use the teaching platform to provide production tools, follow the prompt steps to complete the site initialization, and can flexibly set the curriculum construction projects and parameters, the rapid establishment of course sites. The courses related to industrial design include "Introduction to Industrial Design", "CAD", "Ergonomics", "Composition Foundation", "Sketch", "3D MAX", "3D Print Design", and these courses to share, in the usual teaching process, students can use the network for independent learning, teachers should give the appropriate guidance.

\section{Industrial Design and 3D Printing Teaching System Construction}

Task group organization teachers in-depth enterprise research, refining professional ability; decomposition and refinement of professional ability, for different work tasks using the best learning situation, according to the technical field common ability of curriculum design; employment-oriented, ability-oriented training to build a set of theoretical teaching, based on action-oriented technology core curriculum teaching, comprehensive training, scientific and technological innovation activities such as theory and practice teaching integration, professional teaching and national vocational qualification training intermediation of industrial design higher technology application personnel training program; Focusing on the core curriculum of the curriculum reform, based on the professional post of typical tasks of the work process to build a curriculum system to promote the teaching content curriculum system to further reform and improve the overall teaching level. 
After the investigation and analysis of the research group, the core competence of the industrial design and the professional competence of the 3D course is decomposed into three core professional functions such as product design capability, process product compilation ability and NC product processing ability according to the analysis result of the professional ability analysis. From the basic to the difficult, from the foundation to the complex four-step progressive law, formed by the technical base module, mechanical design and manufacturing capacity module, CAD / CAM capacity module and mold design and manufacturing capacity module composed of "product guide, fourth-order progressive" course study program. On this basis, combined with Xuzhou area to engineering machinery as the leading manufacturing industry, the course knowledge points were effectively combed, so that the content of professional courses "in line with regional development, in line with process standards, in line with production requirements" to build the course of the learning program, the curriculum has a local industry characteristics, product design as the main line of the systematic curriculum system.

Industrial design and 3D course professional core areas of professional learning are: mechanical drawing and drawing, mechanical transmission device analysis and design, precision design and testing of parts, mechanical manufacturing process file reading and editing, CNC machining programming With the operation, Pro / E, Unigraphics, MasterCAM, stamping process and mold design and assembly commissioning, plastic molding process and mold design and assembly commissioning courses.

After teaching practice, now some students show excellent works (Figure 1, Figure 2) as follows:
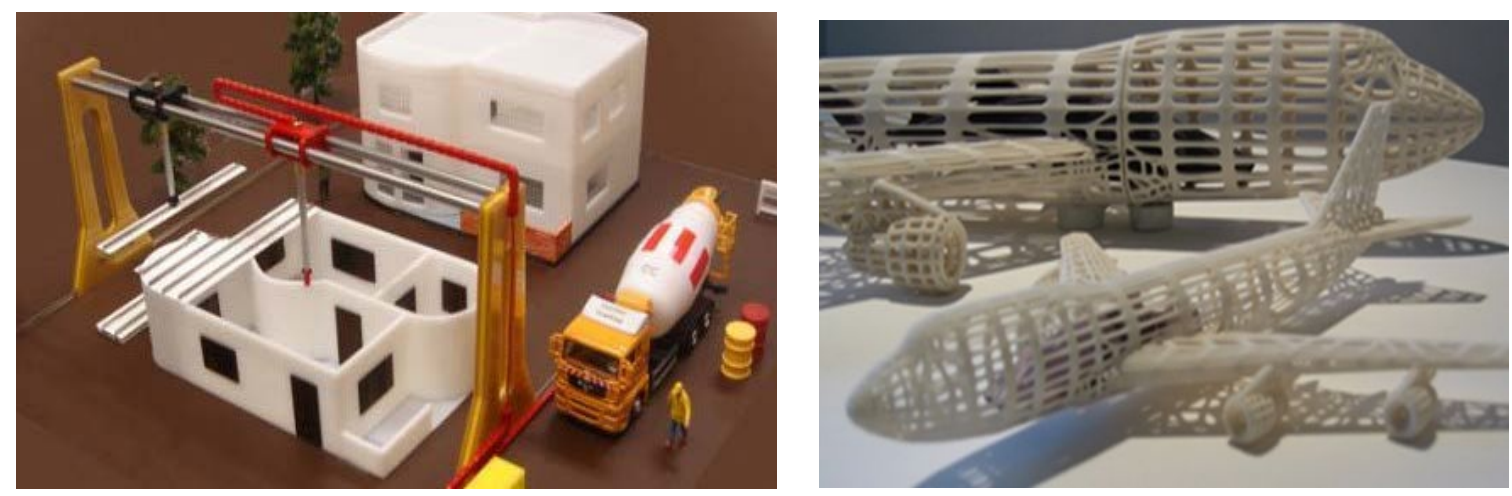

\section{Conclusion}

Through the teaching practice, it is found that the "product guidance and fourth order progressive" teaching method of the industrial design course is very good. The implementation of the teaching mode and the learning efficiency and design ability of the students have greatly improved. Our hospital industrial design and 3D printing professional adhere to the "service for the purpose of employment for the purpose of" principle, in accordance with the "convergence with the market, zero distance employment" development ideas to school-enterprise cooperation as a platform, innovation and combination of personnel training mode , Industrial design will certainly have a vast market in the future, in the future of teaching, industrial design will certainly have new technologies, new inventions, for the existing industrial design course teaching model, will be updated accordingly to improve the teaching needs.

\section{References}

[1] Zhang Dehua; Jiang Yu; Chen Cunwu; Pan Wenlong. Study on the Framework and Teaching Reform of Talent Cultivation of Bioengineering Specialty in Applied Undergraduate Universities [J] .Journal of Anhui University, 2011, (10): 53-56.

[2] Li Peifeng, Sun Yanqiao. Discussion on the Teaching Mode of Mechanical Courses in Technical Colleges [J] .College, 2014 (32): 35-36. 
[3] Li Peifeng. How is information technology applied correctly to the teaching of mechanical courses [J]. Computer age, 2015 (6): 64-65.

[4] Zhu Jing. Work process as the main line of mechanical design and manufacturing professional systematic curriculum system construction [J]. Vocational Education Newsletter, 2011, (3): 5-7. 